\title{
Feasibility of implementing a novel behavioural smoking cessation intervention amongst human immunodeficiency virus-infected smokers in a resource-limited setting: A single-arm pilot trial
}

\begin{tabular}{|c|c|}
\hline $\begin{array}{l}\text { Authors: } \\
\text { Billy M. Tsima } \\
\text { Precious Moe } \\
\text { Joyce Maunge } \\
\text { Kitso Machan } \\
\text { Martha Kgogv } \\
\text { Tebogo Mudo } \\
\text { Joseph Bastia } \\
\text { Warren Bilker } \\
\text { Rebecca Asha } \\
\text { Robert Schnol } \\
\text { Robert Gross }\end{array}$ & 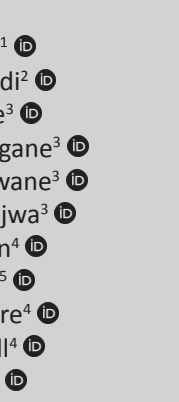 \\
\hline $\begin{array}{l}\text { Affiliations: } \\
{ }^{1} \text { Department } \\
\text { Medicine and } \\
\text { Faculty of Me } \\
\text { University of } \\
\text { Gaborone, Bo }\end{array}$ & $\begin{array}{l}\text { of Family } \\
\text { Public Health, } \\
\text { dicine, } \\
\text { Botswana, } \\
\text { tswana }\end{array}$ \\
\hline $\begin{array}{l}{ }^{2} \text { Princess Mar } \\
\text { Dental Depart } \\
\text { Gaborone, Bo }\end{array}$ & $\begin{array}{l}\text { ina Hospital, } \\
\text { tment, } \\
\text { tswana }\end{array}$ \\
\hline $\begin{array}{l}{ }^{3} \text { Botswana UP } \\
\text { Partnership, } \mathrm{C} \\
\text { Botswana }\end{array}$ & $\begin{array}{l}\text { enn } \\
\text { saborone, }\end{array}$ \\
\hline $\begin{array}{l}{ }^{4} \text { Department } \\
\text { Perelman Sch } \\
\text { University of } \\
\text { Philadelphia, } \\
\text { of America }\end{array}$ & $\begin{array}{l}\text { of Psychiatry, } \\
\text { ool of Medicine, } \\
\text { Pennsylvania, } \\
\text { United States }\end{array}$ \\
\hline $\begin{array}{l}{ }^{5} \text { Department } \\
\text { Epidemiology } \\
\text { Informatics, P } \\
\text { of Medicine, } \\
\text { Pennsylvania, } \\
\text { United States }\end{array}$ & $\begin{array}{l}\text { of Biostatistics, } \\
\text { and } \\
\text { erelman School } \\
\text { University of } \\
\text { Philadelphia, } \\
\text { of America }\end{array}$ \\
\hline $\begin{array}{l}{ }^{6} \text { Department } \\
\text { (ID), Perelman } \\
\text { Medicine, Uni } \\
\text { Pennsylvania, } \\
\text { United States }\end{array}$ & $\begin{array}{l}\text { of Medicine } \\
\text { School of } \\
\text { iversity of } \\
\text { Philadelphia, } \\
\text { of America }\end{array}$ \\
\hline $\begin{array}{l}\text { Research Proj } \\
\text { Project Numb } \\
13 / 18 / 1\end{array}$ & $\begin{array}{l}\text { ect Registration: } \\
\text { er: HPDME }\end{array}$ \\
\hline 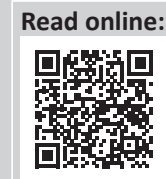 & $\begin{array}{l}\text { Scan this QR } \\
\text { code with your } \\
\text { smart phone or } \\
\text { mobile device } \\
\text { to read online. }\end{array}$ \\
\hline
\end{tabular}

\section{Authors:}

Billy M. Tsima ${ }^{1}$

Kitso Machangane ${ }^{3}$

Martha Kgogwane ${ }^{3}$

Robert Schnoll ${ }^{4}$ (D)

Medicine and Public Health,

Faculty of Medicine,

University of Botswana,

${ }^{2}$ Princess Marina Hospital,

Dental Department,

Gaborone, Botswana

${ }^{3}$ Botswana UPenn

Partnership, Gaborone,

${ }^{4}$ Department of Psychiatry, Perelman School of Medicine, Philadelphia, United States

Epidemiology and

Pennsylvania, Philadelphia,

${ }^{6}$ Department of Medicine

Pennsylvania, Philadelphia

Research Project Registration:

Project Number: HPDME

$13 / 18 / 1$
Background: Tobacco use is prevalent amongst individuals infected with human immunodeficiency virus (HIV). In resource-constrained settings, pharmacological smoking cessation interventions are unfeasible because of their high cost. There is a need to develop and evaluate behavioural interventions to address the unique challenges of tobacco use in the HIVinfected populations in these settings.

Objectives: The authors aimed to assess the feasibility and acceptability of the Behavioural Activation/Problem Solving for Smoking Cessation (BAPS-SC) intervention programme to determine whether it should be tested in an adequately powered randomised controlled trial.

Method: The authors merged behavioural activation therapy (BAT) with the principles of problem-solving therapy to create a novel five-session counselling model to address the unique challenges of tobacco cessation amongst those infected with HIV. Feasibility measures included the rate of enrolment amongst those eligible and the retention rate and descriptive analysis of intervention acceptability. The authors' secondary outcome was 7-day point smoking prevalence abstinence, confirmed with breath carbon monoxide.

Results: A total of 128 individuals were screened over 8 weeks with 50 deemed eligible and 40 enrolled (80\%). Retention at week 12 was 53\% (21/40). The 7 -day point prevalence abstinence, co-confirmed, at week 12 was 37.5\% (15/40). All respondents indicated that they would recommend BAPS-SC to other smokers who want to quit, and would be willing to participate in the programme again up to the point of exit if they did not stop smoking.

Conclusion: A full-scale randomised control trial comparing BAPS-SC with usual practice is warranted to evaluate the efficacy of this novel intervention in these settings.

Keywords: smoking cessation; tobacco; behaviour activation; problem solving; HIV.

\section{Introduction}

The human immunodeficiency virus (HIV) epidemic in sub-Saharan Africa has resulted in a large-scale transformation of healthcare delivery in heavily affected countries such as Botswana. ${ }^{1}$ Unfortunately, other health threats such as cardiovascular disease and cancer have emerged amongst people living with HIV / AIDS (PLWHA) partly because of the chronic inflammation of HIV that is compounded by high rates of smoking in this population. ${ }^{2}$ As such, addressing modifiable cardiovascular risk factors amongst those with HIV infection, including tobacco use, has become a critical priority.,4

Indeed, continued smoking amongst those with HIV infection can result in serious adverse effects, including reduced effectiveness of antiretroviral (ARV) therapy. ${ }^{5}$ Controlling for medication adherence and comorbid illicit drug use, HIV-infected smokers on ARV have a significantly lower likelihood of achieving a viral response and a greater chance of viral or immunologic failure compared with their non-smoking counterparts. ${ }^{6}$ Persistent smoking amongst HIV-infected individuals may also increase progression to acquired immunodeficiency syndrome (AIDS). ${ }^{7}$

Corresponding author: Billy Tsima, btsima@hotmail.com

Dates: Received: 05 Feb. 2020 | Accepted: 08 Mar. 2020 | Published: 24 June 2020

How to cite this article: Tsima BM, Moedi P, Maunge J, et al. Feasibility of implementing a novel behavioural smoking cessation intervention amongst human immunodeficiency virus-infected smokers in a resource-limited setting: A single-arm pilot trial. S Afr J HIV Med. 2020;21(1), a1075. https://doi.org/10.4102/sajhivmed.v21i1.1075

Copyright: ( 2020. The Authors. Licensee: AOSIS. This work is licensed under the Creative Commons Attribution License. 
Pulmonary tuberculosis, a major public health crisis in subSaharan Africa, occurs at higher rates in smokers compared with non-smokers. ${ }^{8}$ Overall, the mortality gains of ARV treatment and the associated improved quality of life amongst those with HIV infection are being jeopardised by the cardiovascular and neoplastic diseases attributable to tobacco use in this population. ${ }^{9}$

Although interest in quitting smoking is high amongst PLWHA, ${ }^{10,11,12}$ particularly when HIV treatment is initiated ${ }^{13}$ and when tobacco use treatment is integrated with HIV care, ${ }^{14}$ remarkably little research has focussed on developing and testing smoking cessation interventions for PLWHA. ${ }^{11}$ Unfortunately, in low-income and developing countries, the costs of pharmacotherapy for nicotine addiction make pharmacological treatments currently inaccessible for PLWHA and further emphasise the importance of novel behavioural strategies.

Depressive symptoms are common in HIV-infected populations, often comorbid with smoking, and associated with poor smoking cessation rates. ${ }^{15}$ Behavioural activation therapy (BAT), rooted in a behavioural economic framework, has been effective at treating depression, and preliminary data in the United States of America (USA) suggests that it may also effectively address smoking. ${ }^{16}$ Behavioural activation therapy aims to increase engagement in healthy rewarding activities (i.e., alternative reinforcers) by reducing patterns of avoidance, withdrawal and inactivity, and to decrease activities that enhance the rewarding aspects of smoking (i.e., complementary reinforcers). Additionally, problem-solving approaches have been used with PLWHA to improve medication adherence and decrease depressive symptoms. ${ }^{17}$ Behavioural activation therapy and problemsolving approach may help smokers select and implement activities that will replace smoking, thereby reducing smoking rates.

The authors developed a novel counselling model incorporating elements of behavioural activation and problem solving to address the unique challenges of tobacco cessation amongst those with HIV infection. They aimed to assess the feasibility and appeal of Behavioural Activation/ Problem Solving for Smoking Cessation (BAPS-SC) intervention to determine whether it should be tested in an adequately powered clinical trial.

\section{Methods}

\section{Participant enrolment}

The authors conducted a single-arm pilot trial of the BAPS-SC intervention in Botswana amongst HIV-infected individuals aged 18-65 years who smoked $\geq 5$ cigarettes/day, on average, at four outpatient HIV clinics. The target accrual goal was 40 participants. This was based on the assumption that at least five participants would be enrolled per week, thus ensuring that the recruitment of human subjects into the trial is timely as this is vital to the success of the trial. ${ }^{18}$ The authors excluded participants if they reported current untreated and unstable alcohol dependence; current use or discontinuation within last 14 days of smoking cessation medications; current diagnosis of unstable and untreated major depression or current or past diagnosis of psychotic disorder; use of chewing tobacco, snuff or snus; current participation in a smoking cessation programme; or plans to use nicotine substitutes or smoking cessation treatments in the next 7 months. The restriction to 7 months was based on the anticipated period to conduct the trial so as to avoid contamination of the intervention with other smoking cessation modalities not under investigation.

A trained recruiter approached each patient in clinic to ascertain smoking status. Those acknowledging smoking were asked to participate in a questionnaire related to their smoking and offered participation in the pilot trial. Those who agreed were referred to the research assistant who arranged to meet with them to determine eligibility and administer informed consent.

\section{Design of intervention}

The authors merged BAT with the principles of problemsolving therapy to create a novel five-session counselling model to address the unique challenges of tobacco cessation amongst PLWHA (BAPS-SC). Members of the team created a formal treatment manual, which was evaluated for cultural appropriateness by Botswana co-investigators, including assessment of translation and back translation and pre-pilot testing using videoconferencing to role play. Key components of BAPS-SC include activity monitoring and rewarding activity scheduling, assessment of personal goals and values, assessment and altering of avoidance behaviour and other maladaptive coping strategies, and contingency management. Behavioural Activation/Problem Solving for Smoking Cessation focuses on reducing stress pile-up and loss of pleasure that accompanies the cessation process and on identifying and establishing environmental/social changes to promote abstinence. Behavioural Activation/Problem Solving for Smoking Cessation addresses smoking as a behaviour that prevents and restricts opportunities for contact with healthy rewarding behaviours. These changes are achieved through altering daily routines previously associated with smoking in ways that increase pleasure and mastery across life domains, reducing rumination and increasing behavioural skills to prevent return to smoking as a means of avoiding stressors.

A pre-quit session (session 1) introduces participants to: (1) self-monitoring of mood and behaviour; (2) assessment of personal values to refine the treatment plan; and (3) scheduling of substitute rewarding activities that align with their abstinence goal. At the target quit date (TQD) session (session 2), participants' experiences with abstinence are reviewed and functional analysis of behaviour is introduced, especially as it relates to smoking and avoidance patterns. Information obtained is used to help generate a tailored behavioural activation plan by using the problemsolving framework to increase rewarding activities and 
relationships, reduce avoidant responses to distressing experiences and facilitate successful implementation of smoking trigger management strategies. Sessions 3-5 incorporate strategies to address avoidance patterns, especially those involving smoking, and replace them with adaptive coping strategies, again by using problem solving. Sessions were conducted by telephone over a 12-week period (with the first session lasting $1 \mathrm{~h}$ and subsequent sessions lasting 30-45 $\mathrm{min}$ on average) and involved weekly homework assignments.

\section{Data collection and management}

Collected data included information related to smoking behaviour (including nicotine dependence measured by the Fagerström Test for Nicotine Dependence $\left.{ }^{19}\right)$, anhedonia [using the Snaith-Hamilton Pleasure Scale (SHAPS) ${ }^{20}$ ] and feasibility (e.g., rate of accrual and retention and appeal of the intervention). Participant accrual rate was defined as the number of participants enrolled over 8 weeks. Retention was calculated as a proportion of participants enrolled who were available at week 12 contact session. Study staff not acting as interventionists interviewed participants at baseline, week 6 and week 12 to determine if they were still smoking and whether they implemented the suggested intervention strategies. The timeline follow-back procedure assessed daily smoking between measurement time points. ${ }^{21}$ Additionally, the amount of carbon monoxide (CO) in participants' breath was tested to confirm self-reported abstinence from tobacco. Data were collected on paper and transferred to an electronic REDCap database for analysis.

\section{Data analysis}

The authors used descriptive statistics to characterise the sample. Feasibility measures included the rate of enrolment and retention and descriptive analysis of intervention acceptability (e.g., whether the participants would have enrolled in the intervention had they known what the experience would be like and whether they would refer a friend who wanted to quit smoking). The primary efficacy outcome was 7-day point prevalence abstinence at week 12 (12 weeks post-TQD), defined as self-reported abstinence for 7 days prior to the assessment and breath $\mathrm{CO}<8$ ppm. ${ }^{22}$ This approach is in line with the recommendations of the working group of the Society for Research on Nicotine and Tobacco based on literature review of abstinence measures used in trials of smoking cessation intervention. ${ }^{23}$

\section{Ethical consideration}

Ethical approval was obtained from the Botswana Ministry of Health (Health Research Unit, reference number: HPDME 13/18/1).

\section{Results}

Characteristics of the sample are described in Table 1. A total of 128 individuals were screened over 8 weeks with 50
TABLE 1: Demographic characteristics.

\begin{tabular}{lcc}
\hline Characteristic & Nor Median & \% or IQR \\
\hline Age in years & 39.5 & 34,48 \\
Male candidates & 38 & 95 \\
Number of cigarettes per day & 10 & $6,11.5$ \\
FTND category at enrolment (week 0) & - & - \\
Low dependence (1-2) & 0 & - \\
Low-to-moderate dependence (3-4) & 0 & - \\
Moderate dependence (5-7) & 37 & 92.5 \\
High dependence ( $\geq 8$ ) & 3 & 7.5 \\
SHAPS score at enrolment & 1.5 & $0.5,2.5$ \\
SHAPS score $>2$ & 10 & 25 \\
\hline
\end{tabular}

IQR, interquartile range; FTND, Fagerstr öm Test for Nicotine Dependence; SHAPS, SnaithHamilton Pleasure Scale (normal = 2 or less; abnormal $=3$ or more).

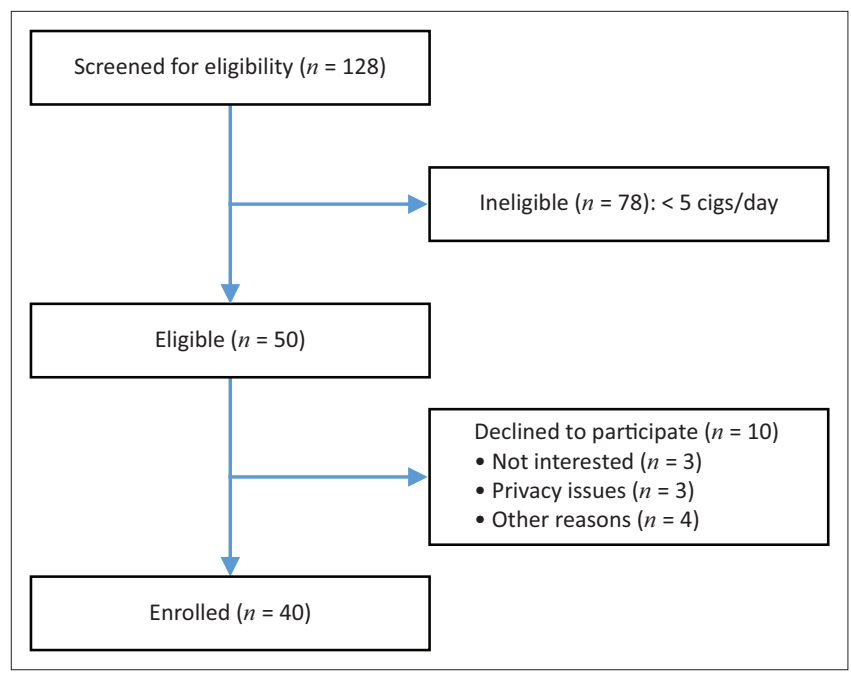

FIGURE 1: Participant flow diagram.

deemed eligible and 40 enrolled (80\%), as shown in Figure 1. Retention at week 12 was $52.5 \%(21 / 40)$.

The 7-day point prevalence abstinence at week 12 was $37.5 \%$ $(15 / 40)$. Notably, all respondents indicated that they would recommend BAPS-SC to other smokers who want to quit and would be willing to participate in the programme again up to the point of exit if they did not stop smoking. When a more stringent threshold of exhaled $\mathrm{CO} \leq 4 \mathrm{ppm}$ was used as the criterion for success, the quit rate in this pilot was $9 / 40(22.5 \%)$.

\section{Discussion}

The authors conducted a single-arm pilot trial of the BAPS-SC intervention programme, a novel behavioural smoking cessation intervention for PLWHA in a high-HIV-burden sub-Saharan country wherein all 40 participants received the intervention. This design is ideal for studies aiming to determine if a novel intervention is appealing and feasible in the setting and warrants a full-scale clinical trial. ${ }^{24}$ The results of the $\mathrm{CO}$ monitoring and exit interviews suggest that BAPS-SC is likely to be efficacious.

This study's results of a high degree of smoking cessation success with BAPS-SC suggest a potentially highly impactful 
smoking cessation programme given that behavioural smoking cessation programmes rarely yield quit rates higher than $10 \%-15 \%{ }^{25}$ There is no comparable trial that tested the intervention developed by the team of the authors with an HIV-negative cohort of smokers. Two comparisons are worth noting, and both indicate a substantial benefit from authors' intervention. Firstly, meta-analyses of behavioural interventions (without medications) for smoking cessation rooted in classic cognitive-behavioural theory show that they yield quit rates of generally less than $15 \%$ at the end of treatment. ${ }^{26}$ Secondly, MacPherson et al. (2010), in their pilot test of BAT for smoking cessation, reported an end-oftreatment quit rate of $17 \% .^{27}$ The authors used a higher threshold of $\mathrm{CO}$ to determine smoking cessation as opposed to a more stringent cut-off in the range of $3 \mathrm{ppm}-4 \mathrm{ppm}$ recently proposed by other researchers. ${ }^{28}$ However, $8 \mathrm{ppm}$ is the cut-off used in most smoking cessation clinical trials for PLWHA, so the authors chose this cut-off to compare their results to the current literature. With regard to past behavioural smoking cessation treatments for PLWHA, a cell phone-based intervention was found to be associated with significantly higher initial quit rates compared with usual care. ${ }^{29}$ Other studies including a group-based tailored intervention, motivational interventions and a web-based intervention (vs in-person or self-help) have not yielded significant increases in quit rates..$^{30,31,32,33,34,35,36}$ Two pilot studies of behavioural treatments that address negative affect (depression and anxiety) show promise for PLWHA. ${ }^{37,38}$

The BAPS-SC trial proved feasible. Firstly, the target sample size of 40 participants was reached within 8 weeks of recruitment, a rate of enrolment that would make large trials feasible. The authors' findings indicated that a large-scale clinical trial would be feasible to determine the efficacy of the BAPS-SC programme in this setting where HIV prevalence is relatively high. Furthermore, smoking prevalence in the setting of their pilot study was estimated to be as high as $51 \%$ for male candidates and $6 \%$ for female candidates with HIV infection. ${ }^{39}$ There were proportionately fewer female candidates enrolled in the present study consistent with data from demographic and health surveys in sub-Saharan Africa. ${ }^{40}$ Although these smoking rates appear to be comparatively lower than reports from North America and Europe, these rates are projected to increase in the African continent whilst they are falling in other parts of the world..$^{40,41}$ Given the limited behavioural health infrastructure in low middle income countries (LMICs) such as Botswana, the authors leveraged HIV clinical care sites and telephone-delivered counselling to extend the reach of skilled practitioners. The authors found this strategy to be effective and acceptable by the participants in the pilot trial.

Smoking is a major cause of morbidity and mortality, yet smokers find it very difficult to quit. If individuals quit because of this intervention, they will reduce their risk of cardiovascular disease, chronic obstructive pulmonary disease and cancers, particularly lung cancer. This will be of direct benefit to the individual participant. Further, if the authors are able to mount a full-scale trial based on the results of this pilot trial, high HIV burden LMICs such as Botswana may benefit because the intervention may become standard of care in the country, reducing disease burden caused by tobacco use. Being a behavioural intervention without pharmacological intervention, the cost is expected to be substantially less with the BAPS-SC compared with a pharmacological intervention. A formal cost-effective analysis will be needed to be undertaken following the roll out of the programme.

Results of the exit questionnaires to evaluate the acceptability of the BAPS-SC trial indicate that HIV-infected smokers in Botswana find the programme to be appealing and acceptable. The results indicate a lower-than-expected retention rate with slightly over half of the participants remaining in the study after a 12-week follow-up period. The retention rates across most smoking cessation trials generally exceed $75 \% .{ }^{42}$ This may be improved by asking participants to provide contact numbers of associates such as friends and family members who can be contacted if the participant is unreachable after a number of attempts and increasing incentives to complete follow-ups. From an evidence-based medicine perspective, if efficacy of the intervention is determined to be high, implementation science methods would need to be employed in the clinical care setting to incorporate the intervention into HIV programmes. The intervention leverages the existing HIV care infrastructure and will likely facilitate scale-up in sub-Saharan African settings where HIV is common and smoking continues to emerge as a threat to HIV-positive individuals' health and survival.

\section{Limitations}

This pilot study evaluating the feasibility of BAPS-SC amongst HIV-infected smokers in Botswana has notable limitations. This was a single-arm trial, and therefore the results indicate only preliminary evidence of efficiency of the intervention and do not confirm efficacy. However, the authors' main aim was to evaluate feasibility of implementing the intervention. The planned full clinical trial informed by these results will be powered to address efficacy. Additionally, the follow-up period was of only 12 weeks as the aim was to evaluate feasibility of the novel intervention. Thus, the follow-up period was not long enough to assess long-term abstinence. However, this was a pilot study to inform a future clinical trial.

\section{Conclusion}

The results of this single-arm pilot trial demonstrate the feasibility of leveraging HIV clinical infrastructure for implementing BAPS-SC as a smoking cessation intervention programme amongst HIV-infected smokers in a resourcelimited setting with high HIV burden. A full-scale clinical trial comparing BAPS-SC with standard counselling is thus warranted to evaluate the efficacy of this novel intervention in these settings. 


\section{Acknowledgements}

The authors would like to thank all the participants who volunteered to participate in the study.

\section{Competing interests}

The authors have declared that no competing interest exists.

\section{Authors' contributions}

B.M.T., R.S. and R.G. designed the study and provided scientific oversight. K.M., J.M., M.K. and T.M. conducted interviews and worked on informed consent and data management. P.M., J.B., W.B. and R.A. contributed to the design of the measures and interpretation of findings. B.T. conducted the primary analysis. B.M.T., R.S. and R.G. drafted the manuscript and incorporated authors' comments. All authors critically reviewed and edited the manuscript. The final manuscript for submission was approved by all authors.

\section{Funding information}

This study was supported by National Institutes of Health (NIH) grants that include HIV Clinical Epidemiology Training for Botswana (D43 TW00978), Penn Center for AIDS Research (P30 AI045008) and Penn Mental Health AIDS Research Center (P30 MH097488).

\section{Data availability statement}

The data used for this analysis are available from the authors upon reasonable request.

\section{Disclaimer}

The views and opinions expressed in this article are those of the authors and do not necessarily reflect the official policy or position of any affiliated agency of the authors.

\section{References}

1. Eyawo O, Franco-Villalobos C, Hull MW, et al. Changes in mortality rates and causes of death in a population-based cohort of persons living with and without HIV from 1996 to 2012. BMC Infect Dis. 2017 Feb 27:17(1):174. https://doi. org/10.1186/s12879-017-2254-7

2. Magodoro IM, Esterhuizen TM, Chivese T. A cross-sectional, facility based study of comorbid non-communicable diseases among adults living with HIV infection in Zimbabwe. BMC Res Notes. 2016 Aug 02;9:379. https://doi.org/10.1186/s13104016-2187-z

3. Reddy KP, Parker RA, Losina E, et al. Impact of cigarette smoking and smoking cessation on life expectancy among people with HIV: A US-based modeling study. J Infect Dis. 2016 Dec 01;214(11):1672-1681. https://doi.org/10.1093/infdis/ jiw430

4. Benard A, Tessier JF, Rambeloarisoa J, et al. HIV infection and tobacco smoking behaviour: Prospects for prevention? ANRS CO3 aquitaine cohort, 2002. Int Tuberc Lung Dis. 2006 Apr 01;10(4):378-383.

5. Pollack TM, Duong HT, Pham TT, Do CD, Colby D. Cigarette smoking is associated with high HIV viral load among adults presenting for antiretroviral therapy in vietnam. PLoS One. 2017 Mar 07;12(3):e0173534. https://doi.org/10.1371/ journal.pone.0173534

6. Feldman JG, Minkoff H, Schneider MF, et al. Association of cigarette smoking with HIV prognosis among women in the HAART era: A report from the women's interagency HIV study. Am J Public Health. 2006 Jun 01;96(6):1060-1065. https:// doi.org/10.2105/AJPH.2005.062745

7. Nieman RB, Fleming J, Coker RJ, Harris JR, Mitchell DM. The effect of cigarette smoking on the development of AIDS in HIV-1-seropositive individuals. Aids. 199 May 01;7(5):705-710. https://doi.org/10.1097/00002030-199305000-00015
8. Bronner Murrison L, Martinson N, Moloney RM, et al. Tobacco smoking and tuberculosis among men living with HIV in johannesburg, south africa: A casecontrol study. PLoS One. 2016 Nov 28;11(11):e0167133. https://doi.org/10.1371/ control study. PLOS On

9. Nahvi S, Cooperman NA. Review: The need for smoking cessation among HIVpositive smokers. AIDS Educ Prev. 2009 Jun 01;21(3 Suppl):14-27. https://doi. org/10.1521/aeap.2009.21.3_supp.14

10. Pacek LR, Cioe PA. Tobacco use, use disorders, and smoking cessation interventions in persons living with HIV. Curr HIV AIDS Rep. 2015 Dec 01;12(4):413-420. https:// doi.org/10.1007/s11904-015-0281-9

11. Pacek LR, Crum RM. A review of the literature concerning HIV and cigarette smoking: Morbidity and mortality, associations with individual- and social-leve characteristics, and smoking cessation efforts. Addict Res Theory. 2015 Feb 01 23(1):10-23. https://doi.org/10.3109/16066359.2014.920013

12. Frazier EL, Sutton MY, Brooks JT, Shouse RL, Weiser J. Trends in cigarette smoking among adults with HIV compared with the general adult population, united states - 2009-2014. Prev Med. 2018 Jun 01;111:231-234. https://doi.org/ 10.1016/j.ypmed.2018.03.007

13. Vidrine DJ, Frank SG, Savin MJ, et al. HIV care initiation: A teachable moment for smoking cessation? Nicotine Tob Res. 2018 Aug 14;20(9):1109-1116. https://doi org/10.1093/ntr/ntx218

14. Pacek $L R$, Rass $O$, Johnson MW. Positive smoking cessation-related interactions with HIV care providers increase the likelihood of interest in cessation among HIVpositive cigarette smokers. AIDS Care. 2017 Oct 01;29(10):1309-1314. https:// doi.org/10.1080/09540121.2017.1330532

15. Ciesla JA, Roberts JE. Meta-analysis of the relationship between HIV infection and risk for depressive disorders. Am J Psychiatry. 2001 May 01;158(5):725-730. https://doi.org/10.1176/appi.ajp.158.5.725

16. Dobson KS, Hollon SD, Dimidjian S, et al. Randomized trial of behavioral activation, cognitive therapy, and antidepressant medication in the prevention of relapse and recurrence in major depression. J Consult Clin Psychol. 2008 Jun 01;76(3): 468-477. https://doi.org/10.1037/0022-006X.76.3.468

17. Gross R, Bellamy SL, Chapman J, et al. Managed problem solving for antiretroviral therapy adherence: A randomized trial. JAMA Intern Med. 2013 Feb 25;173(4): 300-306. https://doi.org/10.1001/jamainternmed.2013.2152

18. Carter RE, Sonne SC, Brady KT. Practical considerations for estimating clinical trial accrual periods: Application to a multi-center effectiveness study. BMC Med Res Methodol. 2005 Mar 30;5:11. https://doi.org/10.1186/1471-2288-5-11

19. Heatherton TF, Kozlowski LT, Frecker RC, Fagerstrom KO. The Fagerstrom test for nicotine dependence: A revision of the Fagerstrom tolerance questionnaire. $\mathrm{Br}$ Addict.1991Sept01;86(9):1119-1127.https://doi.org/10.1111/j.1360-0443.1991. tb01879.x

20. Snaith RP, Hamilton M, Morley S, Humayan A, Hargreaves D, Trigwell P. A scale for the assessment of hedonic tone the Snaith-Hamilton pleasure scale. Br J Psychiatry. 1995 Jul 01;167(1):99-103. https://doi.org/10.1192/bjp. 167.1.99

21. Brown RA, Ramsey SE, Strong DR, et al. Effects of motivational interviewing on smoking cessation in adolescents with psychiatric disorders. Tob Control. 2003 Dec 01;12(Suppl. 4):IV3-IV10. https://doi.org/10.1136/tc.12.suppl_4.iv3

22. Javors MA, Hatch JP, Lamb RJ. Cut-off levels for breath carbon monoxide as a marker for cigarette smoking. Addiction. 2005 Feb 01;100(2):159-167. https:// doi.org/10.1111/j.1360-0443.2004.00957.x

23. Hughes JR, Keely JP, Niaura RS, Ossip-Klein DJ, Richmond RL, Swan GE. Measures of abstinence in clinical trials: Issues and recommendations. Nicotine Tob Res. 2003 Feb 01;5(1):13-25. https://doi.org/10.1080/1462220031000070552

24. Sambucini V. Comparison of single-arm vs. randomized phase II clinical trials: A Bayesian approach. J Biopharm Stat. 2015;25(3):474-489. https://doi.org/10.1 080/10543406.2014.920856

25. Lancaster T, Stead LF. Individual behavioural counselling for smoking cessation, Cochrane Database Syst Rev. 2017 Mar 31;3:CD001292. https://doi.org/10.1002/ 14651858.CD001292.pub3

26. 2008 PHS Guideline Update Panel, Liaisons. Treating tobacco use and dependence: 2008 update U.S. public health service clinical practice guideline executive summary. Respir Care. 2008 Sept 01;53(9):1217-1222.

27. MacPherson L, Tull MT, Matusiewicz AK, et al. Randomized controlled trial of behavioral activation smoking cessation treatment for smokers with elevated depressive symptoms. J Consult Clin Psychol. 2010 Feb 01;78(1):55-61. https:// doi.org/10.1037/a0017939

28. Cropsey KL, Trent LR, Clark CB, Stevens EN, Lahti AC, Hendricks PS. How low should you go? Determining the optimal cutoff for exhaled carbon monoxide to confirm smoking abstinence when using cotinine as reference. Nicotine Tob Res. 2014 Oct 01;16(10):1348-1355. https://doi.org/10.1093/ntr/ntu085

29. Gritz ER, Danysh HE, Fletcher FE, et al. Long-term outcomes of a cell phonedelivered intervention for smokers living with HIV/AIDS. Clin Infect Dis. 2013 Aug 01;57(4):608-615. https://doi.org/10.1093/cid/cit349

30. Balfour L, Wiebe SA, Cameron WD, et al. An HIV-tailored quit-smoking counselling pilot intervention targeting depressive symptoms plus nicotine replacement therapy. AIDS Care. 2017 Jan 01;29(1):24-31. https://doi.org/10.1080/09540121. 2016.1201195

31. Humfleet GL, Hall SM, Delucchi KL, Dilley JW. A randomized clinical trial of smoking cessation treatments provided in HIV clinical care settings. Nicotine Tob Res. 2013 Aug 01;15(8):1436-1445. https://doi.org/10.1093/ntr/ntt005

32. Ingersoll KS, Cropsey KL, Heckman CJ. A test of motivational plus nicotine replacement interventions for HIV positive smokers. AIDS Behav. 2009 Jun 01; 13(3):545-554. https://doi.org/10.1007/s10461-007-9334-4 
33. Lloyd-Richardson EE, Stanton CA, Papandonatos GD, et al. Motivation and patch treatment for HIV+ smokers: A randomized controlled trial. Addiction. 2009 Nov 01;104(11):1891-1900. https://doi.org/10.1111/j.1360-0443.2009.02623.x

34. Manuel JK, Lum PJ, HengI NS, Sorensen JL. Smoking cessation interventions with female smokers living with HIV/AIDS: A randomized pilot study of motivational interviewing. AIDS Care. 2013;25(7):820-827. https://doi.org/10.1080/09540121 .2012.733331

35. Moadel AB, Bernstein SL, Mermelstein RJ, Arnsten JH, Dolce EH, Shuter J. A randomized controlled trial of a tailored group smoking cessation intervention for HIV-infected smokers. J Acquir Immune Defic Syndr. 2012 Oct 01;61(2): 208-215. https://doi.org/10.1097/QAl.0b013e3182645679

36. Stanton CA, Papandonatos GD, Shuter J, et al. Outcomes of a tailored intervention for cigarette smoking cessation among latinos living with HIV/AIDS. Nicotine Tob Res. 2015 Aug 01;17(8):975-982. https://doi.org/10.1093/ntr/ntv014

37. Matthews AK, Conrad M, Kuhns L, Vargas M, King AC. Project exhale: Preliminary evaluation of a tailored smoking cessation treatment for HIV-positive African American smokers. AIDS Patient Care STDS. 2013 Jan 01;27(1):22-32. https://doi org/10.1089/apc.2012.0253
38. O'Cleirigh C, Zvolensky MJ, Smits JAJ, et al. Integrated treatment for smoking cessation, anxiety and depressed mood in people living with HIV: A randomized controlled trial. J Acquir Immune Defic Syndr. 2018 Oct 01;79(2):261-268. https:// controlled trial. J Acquir Immune Defic Syn

39. Mosepele M, Letsatsi V, Mokgatlhe L, Hudson FP, Gross R. Cholesterol screening and statin prescription is low among HIV-infected patients on protease-inhibitor regimens in Botswana. Open AIDS J. 2017 Jun 30;11:45-51. https://doi.org/ 10.2174/1874613601711010045

40. Murphy JD, Liu B, Parascandola M. Smoking and HIV in sub-Saharan Africa: A 25 country analysis of the demographic health surveys. Nicotine Tob Res. 2019 Jul 17;21(8):1093-1102. https://doi.org/10.1093/ntr/nty176

41. WHO Report on the Global Tobacco Epidemic, 2015. Raising taxes on tabacco [homepage on the Internet]. c2015 [cited 2019 Apr 10]. Available from: https:// www.who.int/tobacco/global_report/2015/report/en/

42. Schnoll RA, Goelz PM, Veluz-Wilkins A, et al. Long-term nicotine replacement therapy: A randomized clinical trial. JAMA Intern Med. 2015 Apr 01;175(4): 504-511. https://doi.org/10.1001/jamainternmed.2014.8313 